\title{
VERTdePN Quality Test Procedures of DPF+SCR Systems
}

\section{Jan Czerwinski}

Univ. of Applied Sciences Biel-Bienne

\section{Yan Zimmerli}

Univ. of Applied Sciences

\section{Andreas Mayer \\ TTM}

\section{Norbert Heeb \\ EMPA}

\section{Jacques Lemaire}

AEEDA

\section{Giovanni D'Urbano \\ BAFU}

CITATION: Czerwinski, J., Zimmerli, Y., Mayer, A., Heeb, N. et al., "VERTdePN Quality Test Procedures of DPF+SCR

Systems," SAE Technical Paper 2014-01-1579, 2014, doi:10.4271/2014-01-1579.

Copyright @ 2014 SAE International

\begin{abstract}
The combined exhaust gas aftertreatment systems (DPF+SCR) are the most efficient way and the best available technology (BAT) to radically reduce the critical Diesel emission components particles (PM\&NP) and nitric oxides (NOx). SCR (selective catalytic reduction) is regarded as the most efficient deNOx-system, diesel particle filters are most efficient for soot abatement. Today, several suppliers offer combined systems for retrofitting of HD vehicles.
\end{abstract}

Quality standards for those quite complex systems and especially for retrofit systems are needed to enable decisions of several authorities and to estimate the potentials of improvements of the air quality in highly populated agglomerations.

The present paper informs about the VERTdePN *) quality test procedures, which were developed in an international network project with the same name 2007-2011 (VERT ... Verification of Emission Reduction Technologies; dePN ...

decontamination, disposal of PM / NP and of NOx). Some interesting results of research on the engine dynamometer from the last test period 2011-2013 are given as a complement of the already published results.
The most important statements are:

- the procedures for the quality verification of SCR-, or (DPF+SCR) - systems are developed and confirmed,

- engine dynamometer testing enables the deepest insight in the investigated system concerning: secondary- and nonlegislated emissions, variations of feed factor, analysis on different sampling positions and at specific engine operating conditions (like legal test procedures),

- testing of SCR-systems on vehicle (chassis dynamometer, or road) is important, because of urea dosing, urea mixing and electronic control,

- the filtration efficiency of a DPF is independent of the operating condition (except of regeneration period, or passing over the maximum space velocity),

- the NOx reduction efficiency of SCR-systems is dependent on the operating conditions, because of the optimal temperature window of the SCR-catalysis; at the conditions with exhaust temperature below $200^{\circ} \mathrm{C}$ the urea dosing is stopped.

There is an intense further development of those aftertreatment systems and their electronic control, which opens further potentials of improvements. 


\section{Introduction \& Objectives}

The use of deNOx (especially SCR) systems and the combinations with DPF's offer a large number of variants and technical complexity representing new challenges not only for the manufacturers, but also for the users and for the responsible authorities.

Retofitting with those combined systems is quite challenging and it is possible, in general opinion, mostly through incentives, or restrictions with respect to low emission zones LEZ, [1] and regulations of the respective authorities.

The Swiss Federal Office of Environment BAFU and the Swiss Federal Roads Office ASTRA decided to support the activities of VERT to develop appropriate testing procedures and to define the quality criteria of dePN systems.

Laboratories for IC-Engines and Exhaust Emission Control of the University of Applied Sciences Biel, Switzerland (AFHB) participate since 1992 at the Swiss activities about nanoparticle analytics and DPF verification and since 2006 about the quality of SCR- and (DPF+SCR) - systems.

During the tests additionally to the regulated gaseous emissions several unregulated components such as $\mathrm{NH}_{3}, \mathrm{NO}_{2}$ and $\mathrm{N}_{2} \mathrm{O}$ were measured. The analysis of nanoparticle emissions was performed with SMPS and NanoMet.

The need of testing the SCR-systems together with vehicle became stronger and the supporting Federal Offices accorded a supplementary project TeVeNOx (Testing of Vehicles with NOx reduction systems). In this project 2012-2013 several HD vehicles with SCR (OEM and retrofit) were tested and the test methods on HD chassis dynamometer and on-road were confirmed.

There is an intense research and development of SCR systems and their implementation, $[\underline{2}, \underline{3}, \underline{4}, \underline{5}, \underline{6}, \underline{7}, \underline{8}, \underline{9}, \underline{10}, \underline{11}$, $12,13]$. As effect significant reduction of the target emission parameters is possible.

The objectives of this paper are to show the last state of the VERTdePN testing procedures and to represent some new findings from different research subjects on engine like:

- influences of EGR,

- Ammonium Hydroxide as reduction agent,

- demonstration of $\mathrm{NH}_{3}$-storage,

- crossensitivities of NOx-results,

- cleaning of the system,

- results at different steptests,

- secondary emissions with Cu-Fe-zeolites,

- quality of a retrofit system after 1000 hours.

\section{VERTdePN}

A general objective of VERTdePN is to include the SCR-, or the combined DPF+SCR systems in the test procedures, which were previously developed for DPF retrofitting.

\section{Test Subjects \& Procedures}

For the VERT DPF quality procedure (SN 277206), [14] the research objectives are:

- filtration quality

- durability

- control - \& auxiliary systems, like datalogging and regeneration control

- secondary emissions.

The objectives for a SCR system in the VERTdePN tests are:

- NOx reduction efficiency

- $\mathrm{NO}_{2}$ - and / or $\mathrm{NH}_{3}$ - slip

- emission of $\mathrm{N}_{2} \mathrm{O}$

- operating temperature window

- dynamic operation

- field application \& durability

- auxiliary systems, like datalogging and urea dosing

- further secondary emissions.

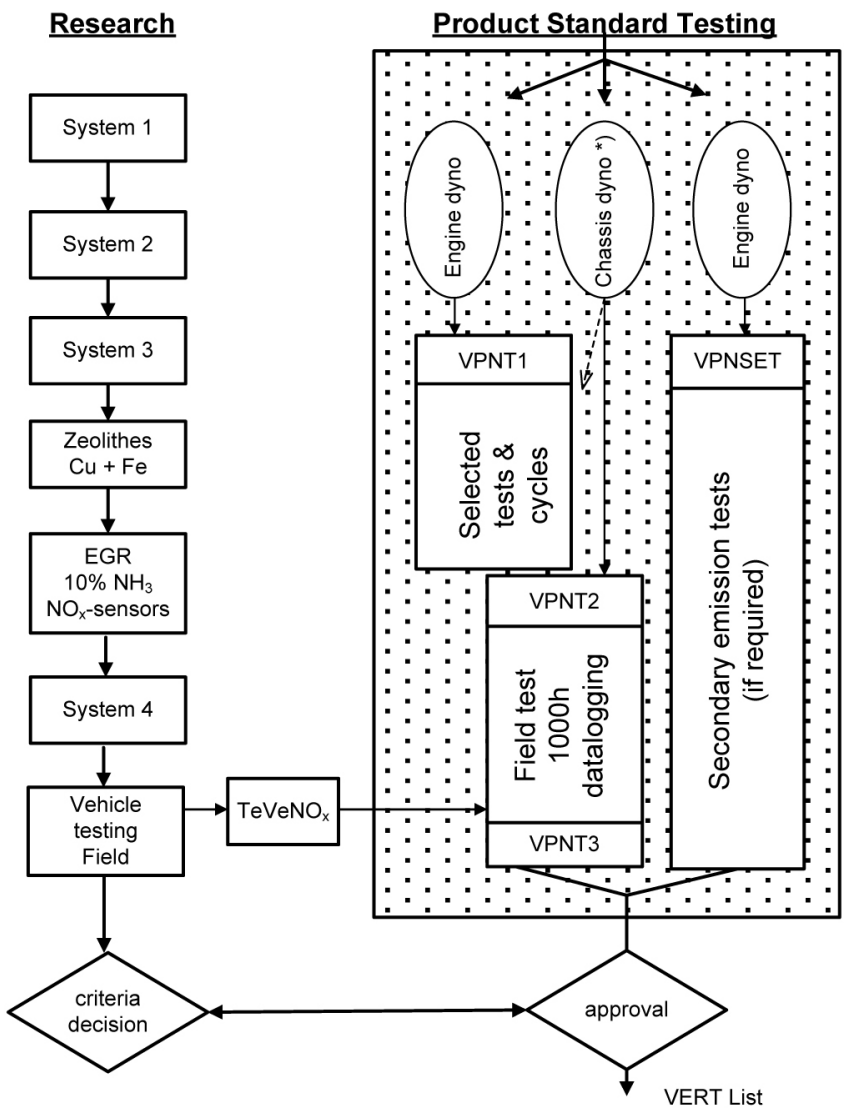

Figure 1. VERTdePN Testing Procedure for DPF+SCR Combisystems Product Standard (DPF VERT certified) 
The main structure of VERTdePN tests for combined DPFSCR is similar, as the preceding VERT activities for DPF.

Fig. 1 shows the scheme of the product standard testing and the main performed subprojects.

There are following test procedures:

1. VERTdePN test 1 (VPNT1) on engine dynamometer, or on chassis dynamometer with equivalent measuring possibilities. VPNT1 contains stationary engine operation in stepstest, including load transitions and urea switch on \& off. Additionally to the reduction efficiencies of $\mathrm{NOx} \& \mathrm{NO}_{2}$, the measurement of some non-legislated emission components is required. These components are: Ammonia $\mathrm{NH}_{3}$ and nitrous oxide $\mathrm{N}_{2} \mathrm{O}$.

If the tested DPF is not yet approved by VERT/OAPC, the measurements of nanoparticles and the estimate of PCFE are necessary.

The demonstration of deNOx-efficiency at dynamic operation (ETC, WHTC, or FIGE) is recommended.

2. VERTdePN Secondary Emissions Test (VPNSET) is applied, if necessary, to state, if there are any potentials of secondary emissions of dioxines and furanes, which are considered as particularly toxic.

VPNSET needs for the analytics of traces a long and well controlled sampling procedure. For this purpose an ISO 8178 8-pts tests, including the load transitions is used. VPNSET can only be performed on engine dynamometer.

3. VERTdePN Test 2 (VPNT2) is performed on vehicle. This is a preliminary control before field test and a real world durability test of $1000 \mathrm{~h}$, or 50 '000 km.

The preliminary control has to be performed on a HD chassis dynamometer at stationary OP's with SWON \& SWOFF and with exhaust gas measuring technics, which enable at least the estimate of the deNOx-rate $\left(\mathrm{KNO}_{\mathrm{X}}\right)$. Also the datalogging, which is prepared for the field test shall be applied and evaluated. The results of the preliminary control are reference values for the final control after field test (VPNT3).

During the field operation a continuous datalogging of NOxsignals before and after system with periodical controls has to be performed. All results of controls, service \& maintenance, or failures shall be documented in a log-book.

4. VERTdePN Test 3 (VPNT3) is a repetition of the preliminary control of VPNT2 on the same chassis dynamometer, at the same operating conditions (OP's \& tamb) and with the same measuring apparatus, in order to demonstrate the system efficiency after the long run.

These test procedures can be used to recognize a product standard and to recommend the retrofit systems to the users.

The formal procedures of approval and the used criteria are to be decided by the implementing authority and are not a subject of this paper.
From the technical points of view some flexibilities of implementing of these test procedures are possible in view of promotion of the retrofitting. This concerns first of all the acceptance of other tests, which were already performed by the manufacturer and which deliver similar information about the system.

It is also to consider that the retrofitting can be done only for certain fleets, which are handled by specialized personnel, which usually have their own quality control and do not need such rigorous OBD measures, like those introduced recently for OEM-SCR applications.

For each retrofitted SCR-system, which is put into operation a simplified acceptance test on vehicle has to be performed. This test consists of checking the datalogger and the urea SWON \& SWOFF during a short road trip and standstill.

\section{Test Cycles}

For the research on engine dynamometer different steady state test procedures can be used. The main objective is to have at least one urea switch-on (SWON) and at least one high load OP during the test.

The first 4-pts test proposed for VPNT1 is represented in Fig. 2., [15].

The four operating points were chosen in such way, that the switching "off" and "on" of the urea-dosing is included in the tests (pt. $7 \rightarrow$ pt. 4 and pt. $4 \rightarrow$ pt. 1).

For basic research of SCR-systems a 6-pts test at constant engine speed was used, Fig. 3, [16], this enabled the representation of results in function of exhaust gas temperature.

If the DPF of a combined system has also to be approved it is necessary to apply the OP's according to the norm, [14]. This requirement leads to the 6-pts test, Fig. 4. In following the result of 4-pts test (Fig. 2) and 6-pts test (Fig. 4) will be compared.

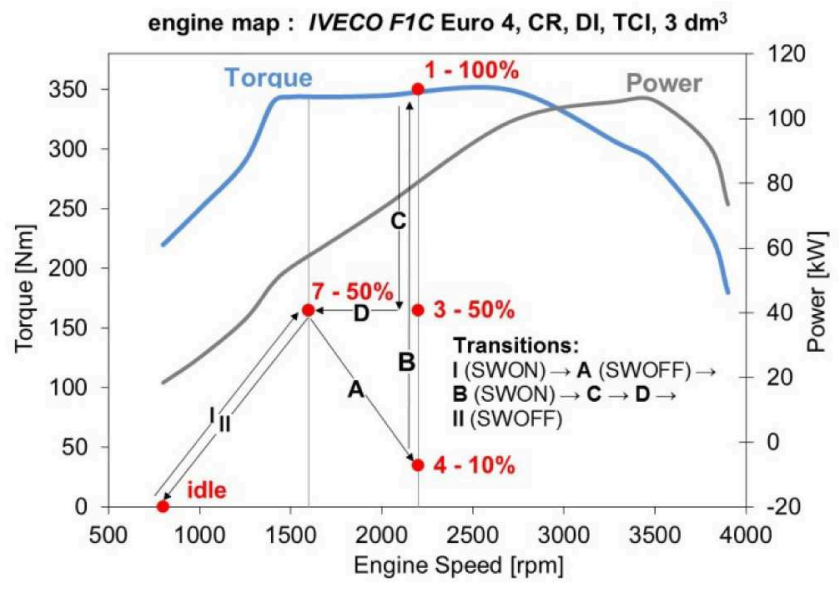

Figure 2. Engine map of the IVECO F1C engine and 4-points test for SCR-investigations 


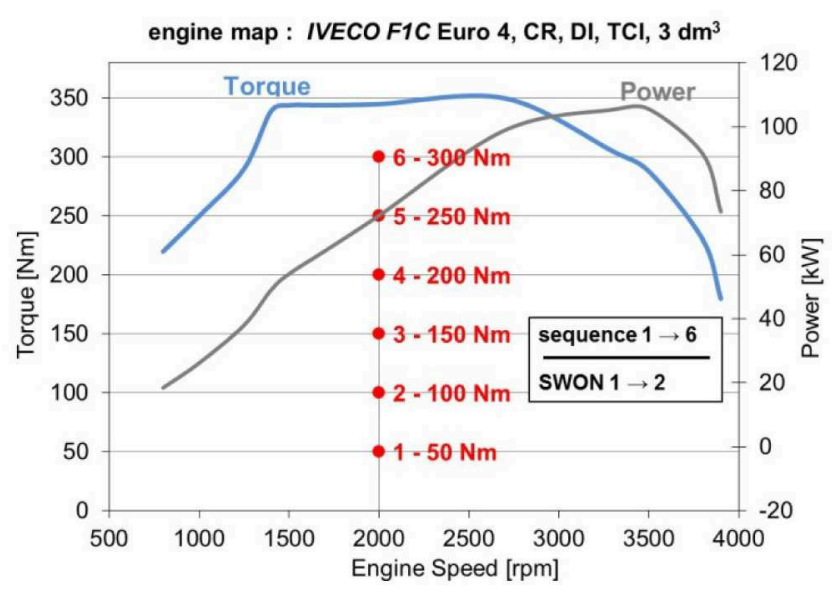

Figure 3. Engine map of the IVECO F1C engine and 6-points steptest for SCR-investigations

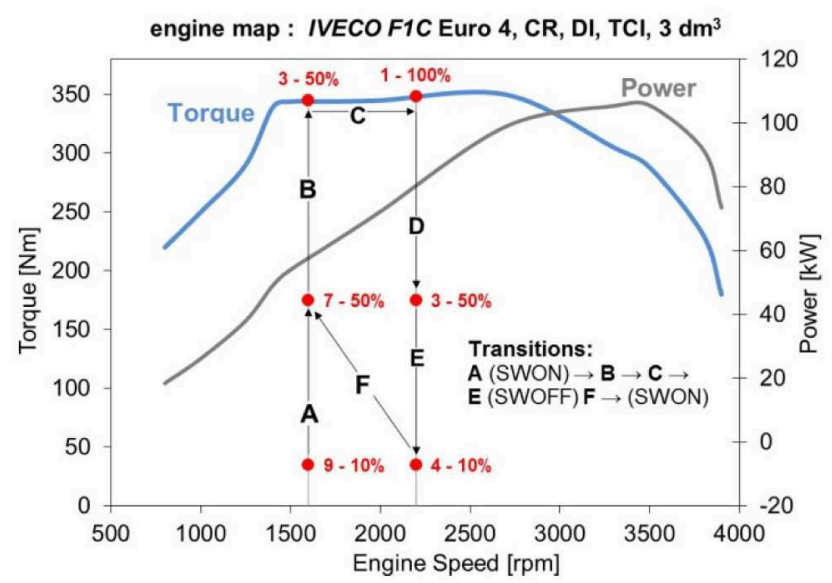

Figure 4. Engine map of the IVECO F1C engine and 6-points test for DPF and SCR-investigations

During the long-duration sampling for VPNSET the ISO 8178 8-pts test is used, [15].

For the dynamic testing on engine dynamometer the European Transient Cycle (ETC) is mostly used, Fig. 5.

All tests are performed in the warm state of the engine and of the exhaust system. As conditioning for a dynamic test cycle the same cycle is used.

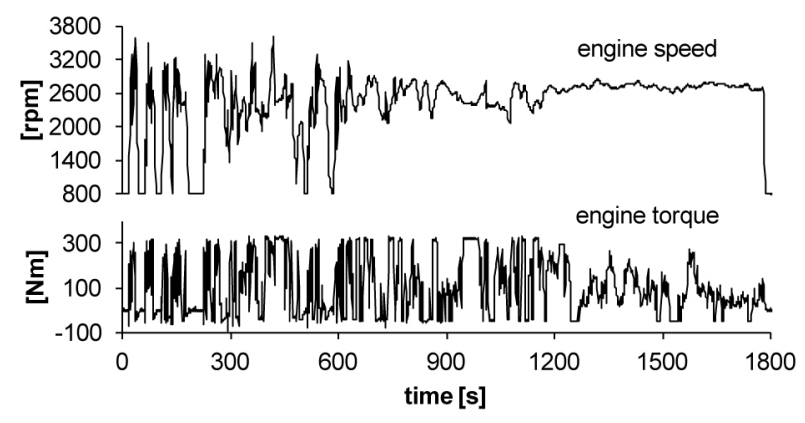

Figure 5. Torque \& Speed in ETC IVECO F1C

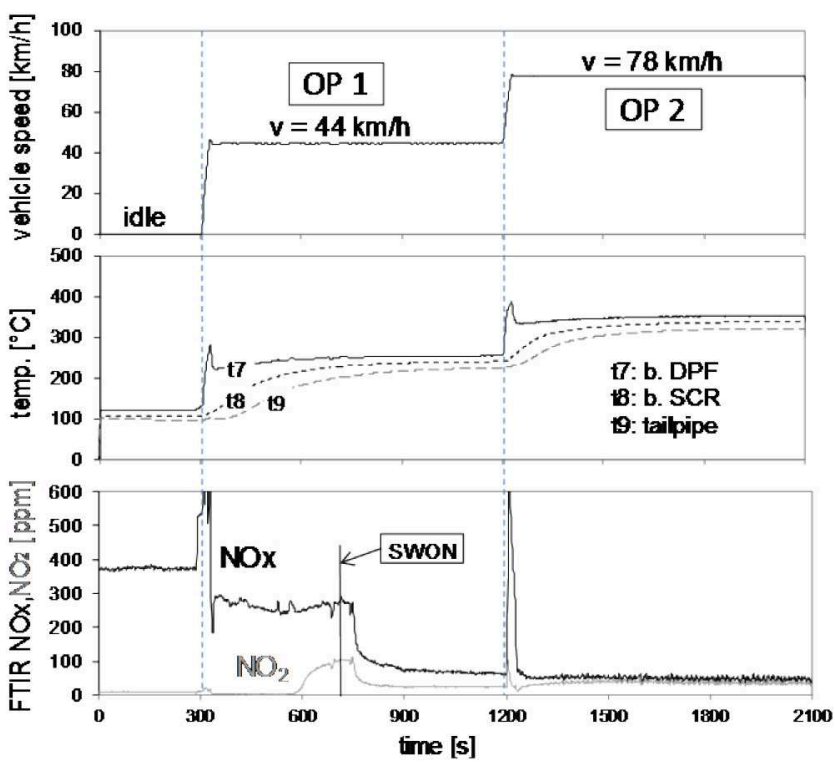

Figure 6. 2-points test for SCR quality control on HD chassis dynamometer

For the preliminary control on vehicle (VPNT2) and for the final control (VPNT3) a simple 2-pts test is used, Fig. 6.

This test is easy to perform on a HD chassis dynamometer in a braking mode. The constant speeds in the range of $50 \mathrm{~km} / \mathrm{h}$ and $80 \mathrm{~km} / \mathrm{h}$ can be slightly adapted according to the best feasibility. The transition from idling to the OP1 provokes the increase of the exhaust temperatures and consequently urea switch-on (SWON), see Fig. 6. The transition from OP2 to idling can be used for retrofit systems as a repetitive switch-off (SWOFF).

During the tests of VERTdePN and TeVeNOx several road tests were performed. These results and experiences will be reported separately.

\section{Previous Results}

Following most important findings from VERTdePN activities, which were published in [15] and [16] are:

- the investigated combined dePN systems (DPF+SCR) for dynamic engine application efficiently reduce the target emissions with deNOx-efficiencies up to $92 \%$ (if operated in the right temperature window) and particle number filtration efficiency up to $100 \%$,

- the average NOx conversion rate at transient operation strongly depends on the operation load profile, on the exhaust gas temperature and the resulting urea dosing control,

- the particle number filtration efficiency, which is verified at stationary engine operation, is valid also at the transient operation,

- secondary nanoparticles are produced due to urea injection, they nevertheless do not impact significantly the overall filtration efficiency of the system (here: DPF upstream \& SCR downstream, differences of PCFE in the range of $0.1 \%)$, 
- the OEM NOx-sensors of the investigated systems are appropriate tools for the in-use control,

- the system with catalyzed DPF (upstream) attains higher overall deNOx-efficiencies due to $\mathrm{NO}_{2}$-production in the DPF,

- for the investigated systems there are no critical emissions of unregulated components, $\mathrm{NH}_{3} \& \mathrm{~N}_{2} \mathrm{O}$.

\section{Tested Engine, Fuel, Lubricant}

\section{Test Engine}

Manufacturer:

Iveco, Torino Italy

Type:

F1C Euro 3 / Euro 4

Displacement:

3.00 Liters

RPM:

max. $4200 \mathrm{rpm}$

Rated power:

Model:

100 kW @ 3500 rpm

4 cylinder in-line

Combustion process:

Injection system

Supercharging:

Emission control:

direct injection

Bosch Common Rail 1600 bar

Turbocharger with intercooling

none

Development period:

Fig. 7 shows the engine and the apparatus for nanoparticle analytics SMPS \& NanoMet in the laboratory for IC-engines, University of Applied Sciences, Biel-Bienne.

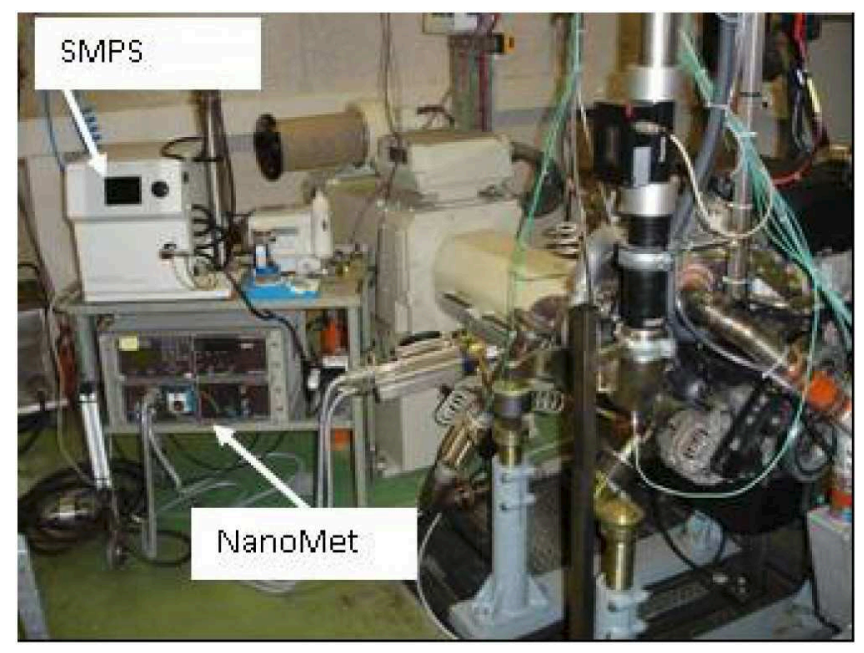

Figure 7. IVECO engine F1C and equipment for nanoparticle measurements in the engine room

\section{Fuel}

Following Diesel fuel was used for the research (Table 1):

- Shell Formula Diesel fuel Swiss market summer quality (10 ppm S) according to SN EN 590

Table 1 represents the most important data of the fuel according to the standards.

Table 1. Fuel properties as per EU-standards.

\begin{tabular}{|lc|c|}
\hline & & Diesel \\
\hline Density $15^{\circ} \mathrm{C}$ & $\mathrm{mm} / \mathrm{ml}$ & 0.832 \\
\hline Viscosity at $40^{\circ} \mathrm{C}$ & & $2.0-4.5$ \\
\hline Flash point & & above $55^{\circ} \mathrm{C}$ \\
\hline Cloud point & $\%$ & $\max -10^{\circ} \mathrm{C}$ \\
\hline Filterability CFPP & $\mathrm{ppm}$ & $\max -20^{\circ} \mathrm{C}$ \\
\hline Ash & & $<10$ \\
\hline Sulfur & & 51 \\
\hline Cetane number & $\mathrm{MJ} / \mathrm{kg}$ & 42.7 \\
\hline Calorific value & in $\%$ & 86.7 \\
\hline $\mathrm{C}$ fraction & in $\%$ & 13.3 \\
\hline $\mathrm{H}$ fraction & in $\%$ & 0 \\
\hline O fraction & $\mathrm{kg} / \mathrm{kg}$ & 14.52 \\
\hline Air ${ }_{\text {min }}$ & & $180-340$ \\
\hline Boiling range $10-90 \%{ }^{\circ} \mathrm{C}$ & & \\
\hline
\end{tabular}

\section{Lubricant}

For all tests a lubeoil according to the manufacturers requirements Mobil 1 ESP Formula $5 \mathrm{~W}-30$ was used.

Table 2 shows the available data of this oil,

ACEA classes: C3, A3, B3/B4,

API classes: SL / SM; CF

Table 2. Data of the utilized oil (* analysis, others: specifications)

\begin{tabular}{|l|c|c|}
\hline Property & Mobil oil & \\
\hline Viscosity kin $40^{\circ} \mathrm{C}$ & 72.8 & $\mathrm{~mm}^{2} / \mathrm{s}$ \\
\hline Viscosity kin $100^{\circ} \mathrm{C}$ & 12.1 & $\mathrm{~mm}^{2} / \mathrm{s}$ \\
\hline Viscosity index & 164 & $(--)$ \\
\hline Density $15^{\circ} \mathrm{C}$ & 0.85 & $\mathrm{~kg} / \mathrm{m}^{3}$ \\
\hline Pourpoint & -45 & ${ }^{\circ} \mathrm{C}$ \\
\hline Flamepoint & 254 & ${ }^{\circ} \mathrm{C}$ \\
\hline Total Base Number TBN & 6 & $\mathrm{mg} \mathrm{KOH} / \mathrm{g}$ \\
\hline Sulfur ashes & & \\
\hline Sulfur & & $\mathrm{mg} / \mathrm{kg}$ \\
\hline MG $^{*}$ & 2000 & $\mathrm{mg} / \mathrm{kg}$ \\
\hline MO $^{*}$ & 41 & $\mathrm{mg} / \mathrm{kg}$ \\
\hline $\mathrm{Zn}^{*}$ & 80 & $\mathrm{mg} / \mathrm{kg}$ \\
\hline Ca $^{*}$ & 900 & $\mathrm{mg} / \mathrm{kg}$ \\
\hline $\mathrm{P}^{*}$ & 1100 & $\mathrm{mg} / \mathrm{kg}$ \\
\hline
\end{tabular}




\section{Engine Version Euro 4}

In collaboration with the engine manufacturer the research engine version Euro 3 was upgraded to the version Euro 4.

The new engine equipment consisted of:

- EGR valve (high pressure EGR), (see Fig. 8)

- EGR cooler,

- throttle valve at intake,

- air mass flowmeter at intake

- injectors

- new engine calibration (ECU) for modifications of injection timing and injection mode (pre-/post-injections).

The principal influences on engine combustion and emissions are:

- HP EGR regulated continuously in the engine map,

- further use of potentials of CR-injection system (pressure, timing, shaping, strategies).

The EGR is regulated by means of simultaneous positioning of the EGR-valve and of the throttle valve with air mass flow as guiding parameter. The total injected fuel quantity is adapted to the air mass flow.

The ECU-engine calibration is given in two versions: for HDand for LD-application. In the present work only the HD-version was used.

The research laboratory received access to the ECU with the possibility of switching on/off EGR.

The engine version Euro 4 with EGR is abbreviated to E4 in this paper and the same version with EGR switched off is called $\mathrm{E}(4)$.

\section{Measuring Set-Up and Instrumentation}

\section{Engine Dynamometer and Standard Test Equipment}

Fig. 8 represents the special systems installed on the engine, or in its periphery for analysis of the regulated and unregulated emissions.

Laboratory equipment employed:

- Dynamic test bench Kristl \& Seibt with force transducer HBM T10F

- Tornado Software Kristl \& Seibt

- Fuel flow measurement AIC 2022

- Air mass meter ABB Sensiflow P

- Pressure transducers Keller KAA-2/8235, PD-4/8236

- Thermo-couples Type K.

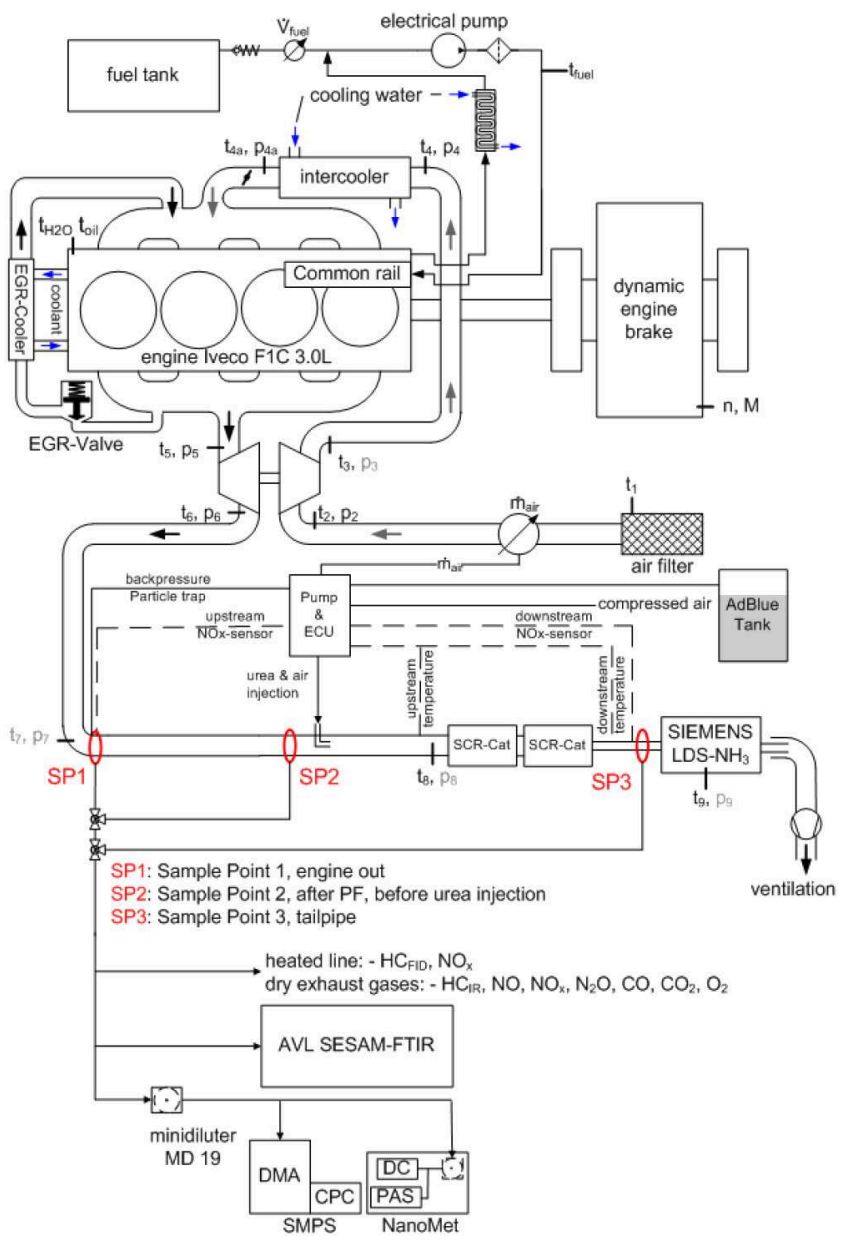

Figure 8. Engine dynamometer and test equipment

\section{Test Equipment for Exhaust Gas Emissions}

Measurement is performed according to the exhaust gas emissions regulations for heavy duty vehicles which are also in force in Switzerland (Directive 2005 / 55 / CE \& ISO 8178):

- Volatile components:

- Horiba exhaust gas measurement devices

Type: VIA-510 for $\mathrm{CO}_{2}, \mathrm{CO}, \mathrm{HCIR}, \mathrm{O}_{2}$,

Type: CLA-510 for NO, NOx

- Amluk exhaust gas measurement device Type:

FID 2010 for HCFID,

- $\mathrm{NH}_{3}$ and $\mathrm{N}_{2} \mathrm{O}$ :

With SCR several unregulated and secondary pollutants can be produced. The slip of gaseous components such as ammonia $\mathrm{NH}_{3}$ and nitrous oxide $\mathrm{N}_{2} \mathrm{O}$ was measured by means of:

- Siemens LDS 6 Laser Analyzer 7MB 6021, $\mathrm{NH}_{3}$

- Siemens ULTRAMAT 6E 7MB2121, $\mathrm{N}_{2} \mathrm{O}$

- Eco physics CLD $822 \mathrm{CM}$ hr with hot line for $\mathrm{NO}, \mathrm{NO}_{2}$, $\mathrm{NO}_{3}, \mathrm{NH}_{3}$

- FTIR (Fourier Transform Infrared) Spectrometer (AVL SESAM) with the possibility of simultaneous, time-resolved measurement of approx. 30 emission components - among those validated are: $\mathrm{NO}, \mathrm{NO}_{2}, \mathrm{NOx}, \mathrm{NH}_{3}, \mathrm{~N}_{2} \mathrm{O}$. 


\section{Particle Size Analysis}

The particle size and number distributions were analysed with following apparatus, Fig. 7:

- SMPS - Scanning Mobility Particle Sizer, TSI (DMA TSI 3071, CPC TSI 3025 A)

- NanoMet - System consisting of:

- PAS - Photoelectric Aerosol Sensor (EcoChem PAS 2000 ) indicates the carbonaceous total surface of the aerosol

- DC - Diffusion Charging Sensor (Matter Eng. LQ1-DC) indicates the totale surface of the aerosol independently of the chemical properties

- MD19 tunable minidiluter (Matter Eng. MD19-2E)

The nanoparticle results represented in this paper are obtained with sampling at tail pipe with MD19 and with

thermoconditioner $\left(300^{\circ} \mathrm{C}\right)$. The nanoparticulate measurements were performed at constant engine speed (warm) with SMPS and NanoMet.

During the dynamic engine operation NanoMet and CPC were used.

\section{Results}

Following the results of some specific research subjects, which may complete or enlarge the present state of knowledge, will be shortly presented.

\section{Influences of EGR \& SCR on NOx \& NP}

\section{Comparisons of Engine Versions Euro 3 - Euro 4 Iveco F1C}

The different variants of engine setting were shortly designated as: E3 (Euro 3 without EGR), E4 (Euro 4 with specific equipment, and with $E G R$ active) and $E$ (4) (engine version Euro 4, but with deactivated, closed EGR).

EGR lowers generally the NOx-emissions, with almost no influence on CO \& HC. With EGR there is less gas flow through the engine, lower boost pressure and lower backpressure. At higher engine loads there are also higher engine out exhaust gas temperatures with EGR.

The differences between the variants $E 3$ and $E(4)$ (EGR valve closed) result mainly from the changed injection parameters (injectors, geometry, pressure, rate shaping, timing) and influences on boost pressure (intake collector, intercooler, operating conditions of the turbocharger).

Fig. 9 demonstrates an example of an EGR switch off at OP3 $(50 \%)$.
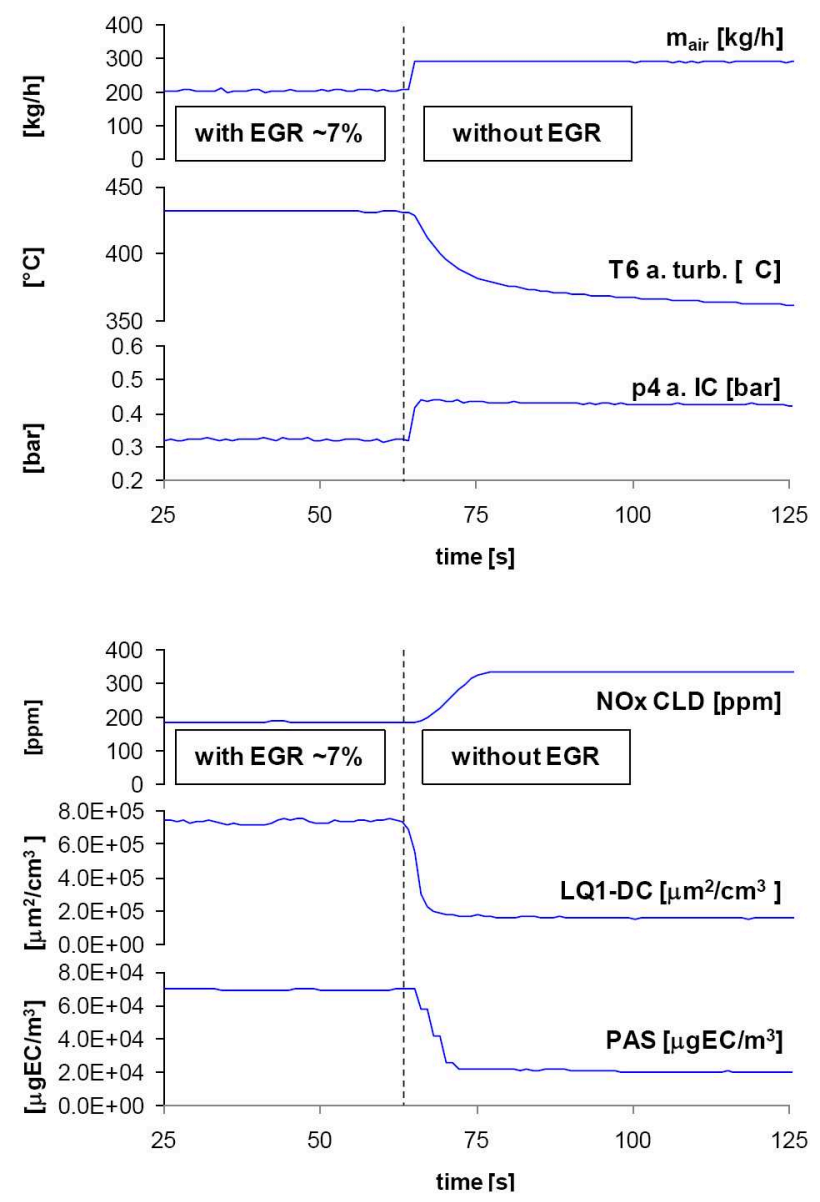

Figure 9. Switch off EGR mode at 2200 rpm / 162 Nm Iveco F1C E4; Diesel; w/o exhaust gas aftertreatment system

Looking on these plots from right to left it can be summarized that:

- EGR lowers NOx and increases PAS \& DC (NP),

- EGR reduces the gas throughput through the engine,

- EGR lowers the boost pressure and the backpressure,

- EGR increases the exhaust gas temperature.

PAS (photoelectric aerosol sensor) is sensitive to the surface of particulates and to the chemical properties of the surface. It indicates the solid carbonaceous particles. DC (diffusion charging sensor) measures the total active particle surface independent of the chemical properties. It indicates the solids and the condensates.

All signals of PAS and DC in this figure are converted to the values responding to the undiluted volume concentrations in the exhaust gas.

The NanoMet results usually confirm the findings from SMPS and are regarded, especially $\mathrm{DC}$, as parameters substituting the NP-count concentration measurement. 
Fig. 10 gives example of SMPS PSD-spectra with different engine variants at middle load (OP3, 50\% load). The PSD are represented in linear and in logarithmic scale to demonstrate the appearance of different kind of representations. The NP count concentrations show a little difference between the engine versions E3 2008 (Euro 3 w/o EGR) and E(4) (Euro 4 with closed EGR). The opening of EGR (version E4) causes a clear increase of NP numbers, with a maximum in the size range $70-80 \mathrm{~nm}$.

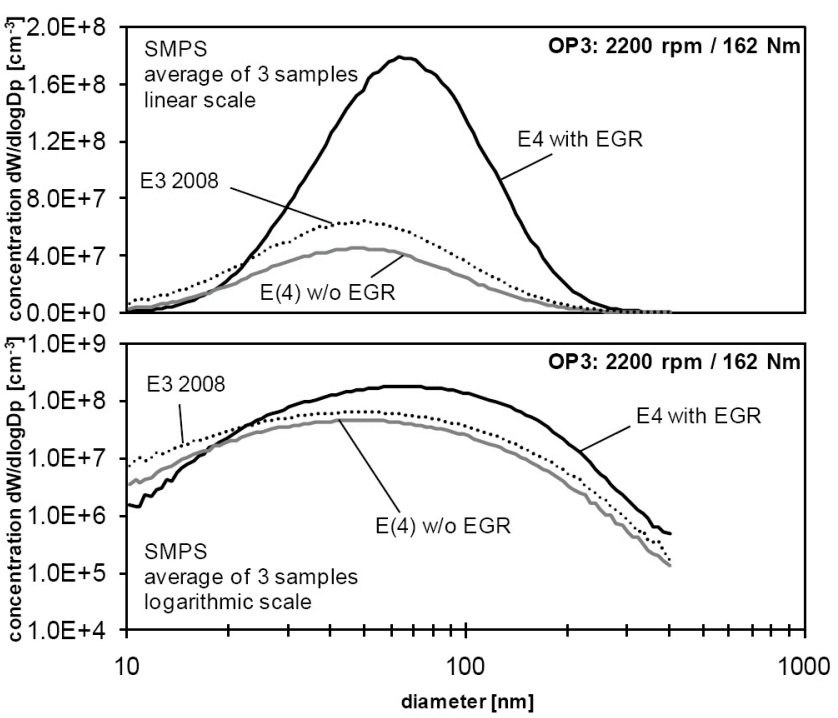

Figure 10. Influence of EGR on nanoparticle emissions, Iveco F1C E4; diesel; w/o exhaust gas aftertreatment system

The EGR-rates on this engine version were not very high (up to $13 \%$ at $2200 \mathrm{rpm}$ ), as well as the effects of reducing NOx. A comparison of results at 4-pts test $(20 \%, 30 \%, 50 \% \& 100 \%$ load at $2200 \mathrm{rpm}$ ) and in ETC was performed and the average influences on NOx \& NP can be summarized in the Table 3:

Table 3. Average reduction rates of NOx \& NP (NP are increased by EGR).

\begin{tabular}{|l||l|l|}
\hline K $_{\text {NOx }}[\%]$ & EGR & SCR \\
\hline \hline 4-pts & 18.9 & 60.8 \\
\hline ETC & 22.6 & 72.3 \\
\hline K $_{\text {PC }[\%]}$ & EGR & SCR \\
\hline \hline 4-pts & -43.1 & 15.7 \\
\hline ETC & -43.9 & 14.9 \\
\hline
\end{tabular}

With SCR there is a slight tendency of reduction of the NP count concentrations - diffusion loses in the SCR catalysts. This is a typical result for all catalysts with open channels.
The influences of EGR can be summarized:

- the NOx reduction potentials in ETC on the investigated engine are:

EGR reduces NOx approx. in the range of $22 \%$; SCR is the strongest reduction measure in the range of $72 \%$.

- the influences on nanoparticles counts emissions (PC) in ETC are:

EGR 44\% increase, SCR 15\% reduction.

\section{Ammonium Hydroxide as Reduction Agent}

For research of $\mathrm{NOx}$-reduction rates with $\mathrm{NH}_{3}$-water-solution a $10 \%$ solution was used.

$\mathrm{NH}_{3}$ reacts with water and is present as Ammonium Hydrate (or: Ammonium Hydroxide, $\mathrm{NH}_{4} \mathrm{OH}$ ). This liquid is hazardous for the health in all possible contacts - inhalation, skin, eyes and ingestion and is not recommended for a general use on the market.

With both reduction agents a similar test was performed: At an OP $2200 \mathrm{rpm} / 165 \mathrm{Nm}$, with texh before SCR $375^{\circ} \mathrm{C}$ the reduction agent injection $\mathrm{RAI}$ was activated and interrupted in intervals. The consecutive RAl's were (in general) with growing feed factor " $\alpha$ ". The resulting emissions were measured with FTIR, CLD and UDS-NOx-sensors and the $\mathrm{K}_{\mathrm{NOx}}$-values of each method were estimated. During each variant of reduction agent dosing (each $\alpha$ ) the SMPS measurements of nanoparticle size distributions (PSD) were performed.

In order to obtain a stoichiometric feed factor with $10 \%$ solution Ammonium Hydroxide $\left(10 \% \mathrm{NH}_{3}\right)$ it is necessary to increase the injected volumetric flow, comparing to AdBlue, by approx. factor 4. The reasons are: higher dilution of $\mathrm{NH}_{3}$, than urea $\left(\mathrm{NH}_{2}\right)_{2} \mathrm{CO}$ and the double source of $\mathrm{NH}_{3}$-molecule from 1 urea-molecule.

Fig. 11 shows an example of $\alpha$-variation at a constant OP with AdBlue and $\left(10 \% \mathrm{NH}_{3}\right)$.

With overdosing of $\left(10 \% \mathrm{NH}_{3}\right)$, there are $\mathrm{K}_{\mathrm{Nox}}$-values up to $100 \%$, with a very low Ammonia slip $\mathrm{NH}_{3}$ max up to $7 \mathrm{ppm}$ (FTIR \& CLD). There are no emissions of Formaldehyde, or Hydrocyanic-, Formic-, or Isocyanic- Acids.

Due to the high amount of water with $\left(10 \% \mathrm{NH}_{3}\right)$ lower $\mathrm{NH}_{3}-$ readings of FTIR and slightly higher levels of secondary nanoparticles were found.

It can be stated, that in the useful range of the feed factor $\alpha$ around 0.8 there is a slightly lower $\mathrm{K}_{\mathrm{NOx}}$ with $\left(10 \% \mathrm{NH}_{3}\right) ; \Delta$ $\mathrm{K}_{\text {NOX }} \approx 1-3 \%$. With $\left(10 \% \mathrm{NH}_{3}\right)$ there are also slightly higher values of $\mathrm{NOx} \& \mathrm{NO}_{2}$, but there is almost no $\mathrm{NH}_{3}$-slip approaching the stoichiometric feed factor $\alpha=1$. 

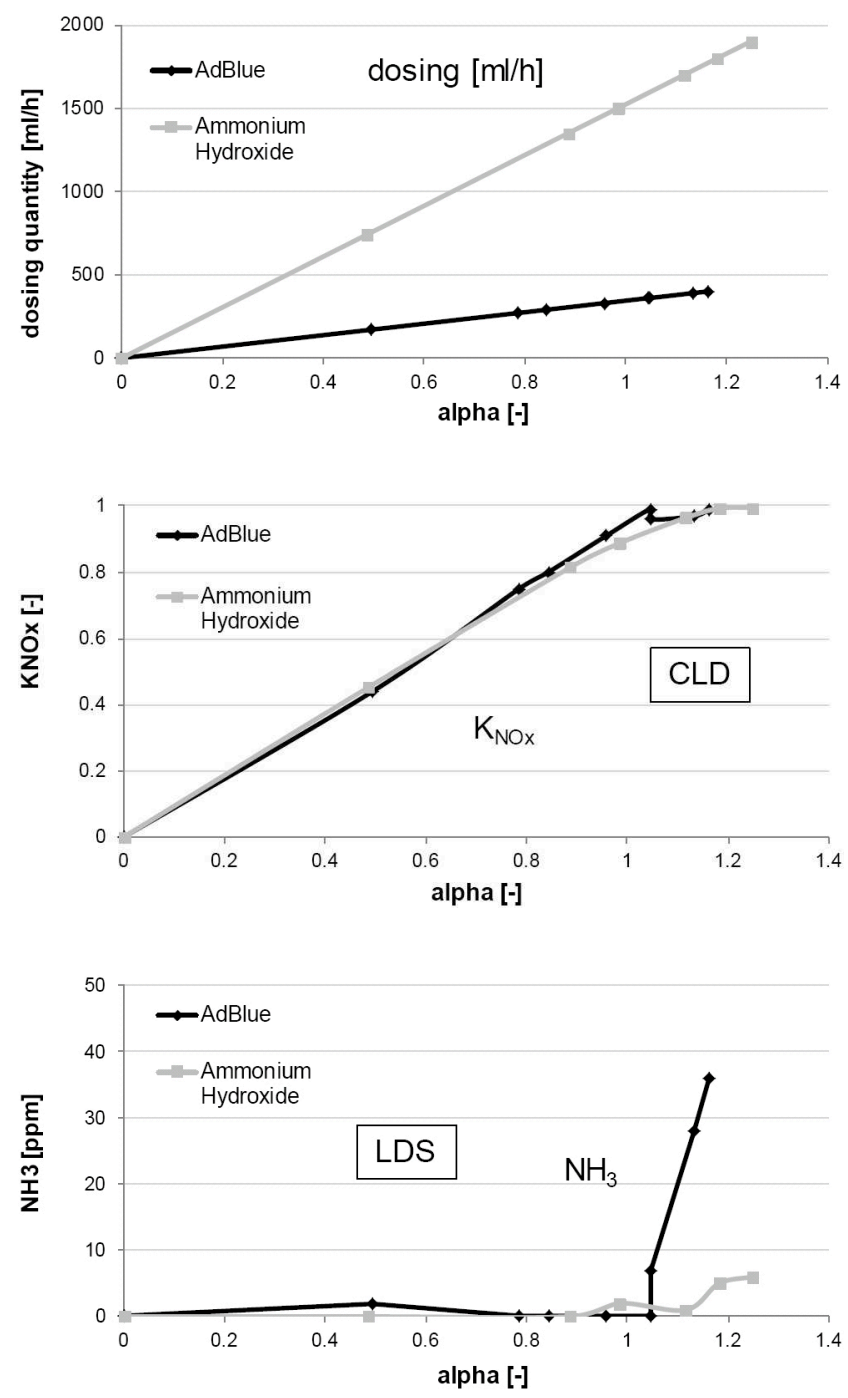

Figure 11. Variation of a with AdBlue vs. Ammonium Hydroxide. DPF \& SCR-catalyst, IVECO F1C, E(4), ULSD

\section{Demonstration of $\mathrm{NH}_{3}$-Storage}

For the electronic control of AdBlue ${ }^{\circledR}$ dosing of SCR systems several physico-chemical processes have to be considered, like: AdBlue mixture preparation, transformation of AdBlue in Ammonia (thermolysis \& hydrolysis) and store /release of Ammonia in the SCR-catalyst. The best AdBlue dosing is reached, when with the variable engine-out NOx emissions in the engine map and also in transient engine operation the maximum NOx conversion rates with possible no $\mathrm{NH}_{3}$-slip are reached.

The effects of $\mathrm{NH}_{3}$-storage were studied and an example of the most significant results is represented here. Fig. 12 shows urea switching on and off at constant low-load OP 2200 rpm / 80 $\mathrm{Nm}$. The objective was to leave enough time to stabilize the emissions after urea switch on (SWON). The diagram represents 1 hour run.
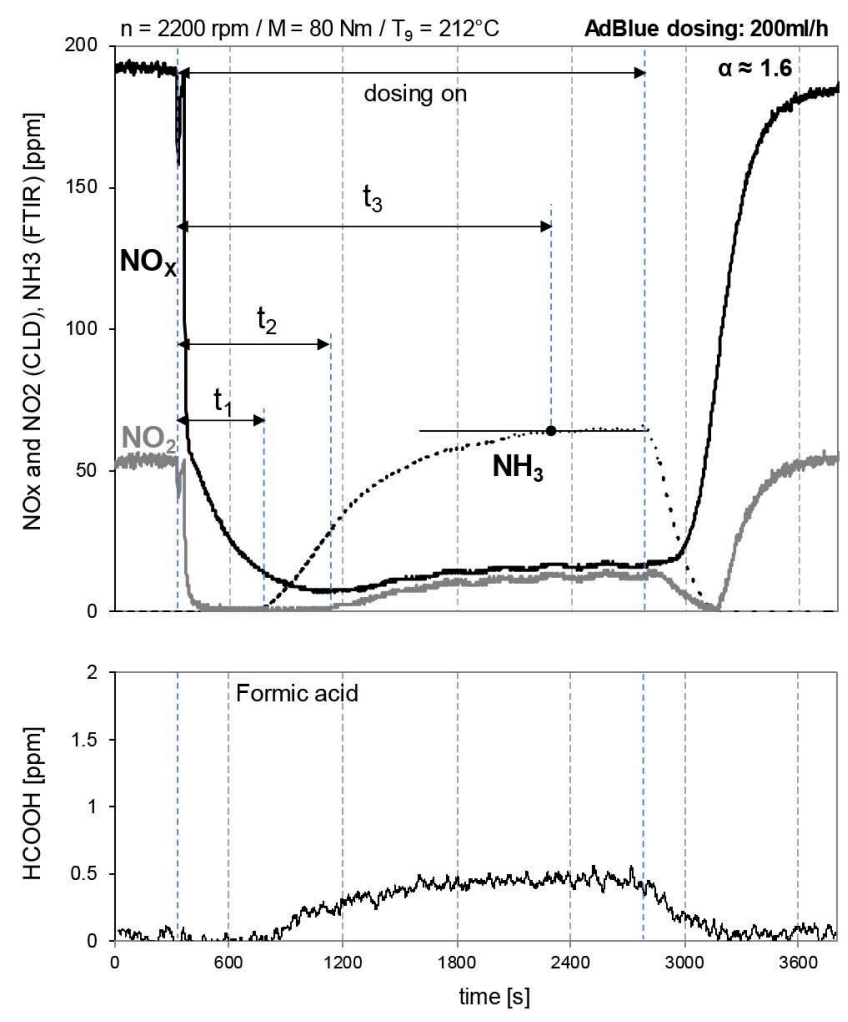

Figure 12. Urea dosing SWON \& SWOFF at low-load OP. DPF \& SCR-catalyst, AdBlue; IVECO F1C, E(4), ULSD

In the short time (approx. 20s) after SW on there is a "quick" reduction of approximately $75 \%$ of initial NOx and totality of $\mathrm{NO}_{2}$. $\mathrm{NO}_{2}$ supports the quicker deNOx-reactions and from the instant, when $\mathrm{NO}_{2}$ is consumed the further $\mathrm{NOx}$-reduction slows down - the last quarter of NOx-reduction takes the time "t2" (approx $13.3 \mathrm{~min}$ ).

After the time " $\mathrm{t} 1$ " (approx. $7.5 \mathrm{~min}$ ) $\mathrm{NH}_{3}$ starts to increase. It is no more totally needed for deNOx-reactions, part of it is stored in the SCR-catalyst, part of $\mathrm{NH}_{3}$ is available for the negligible production of Formic Acid and the rest is emitted. It can be assumed that after time "t3" (approx. $32 \mathrm{~min}$ ), when the $\mathrm{NH}_{3}$-emission level stabilizes, the storage capacity is filled out.

The increase of NOx- and $\mathrm{NO}_{2}$ - concentrations (CLD) after time "t2" is due to the presence of $\mathrm{NH}_{3}$ and to the crossensitivity of CLD against $\mathrm{NH}_{3}$ (see following section).

Some tests were performed, when after $\mathrm{NH}_{3}$-storage period and after SWOFF at lower OP1 (80 Nm) time was left to stabilize the emission and after that a load jump to the higher OP2 $(250 \mathrm{Nm}$ ) was performed, still without RAI (see Fig. 16). This provoked a sudden increase of NOx-emissions, but due to the increasing temperature and some release of $\mathrm{NH}_{3}$ there is a break-down of NOx-emissions during certain time period after the maximum of NOx, Fig. 13. This was a clear and repetitive demonstration of $\mathrm{NH}_{3}$-release. Similar tests were performed without previous urea dosing and consequently without $\mathrm{NH}_{3}$-storage. 
Fig. 13 shows NOx-emission at load-jump with and without $\mathrm{NH}_{3}$-release. The lower $\mathrm{NOx}$-values are an effect of $\mathrm{NH}_{3}-$ release. This is particularly visible, when there is significant increase of exhaust temperature. When the temperature starts to stabilize, the $\mathrm{NH}_{3}$-release stops.
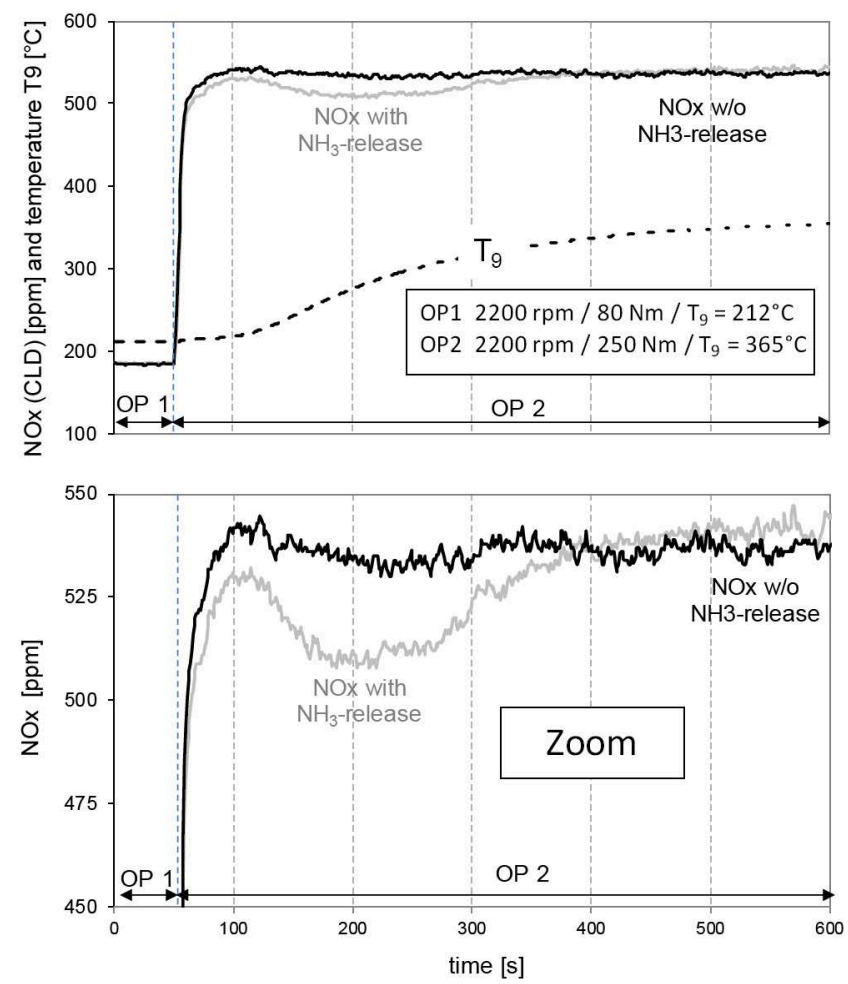

Figure 13. Ammonia storage: $\mathrm{NOx}$ at load-jump with / without $\mathrm{NH}_{3}{ }^{-}$ release. DPF \& SCR-catalyst, AdBlue dosing off; IVECO F1C, E(4), ULSD

\section{Crossensitivities of NOx-Results}

During the tests of different exhaust aftertreatment systems a lot of NOx-data were obtained with different measuring devices: CPK (or UDS) sensors, CLD and FTIR.

In a study work the data were evaluated from the point of view of measured differences depending on $\mathrm{NO}_{2}$, or $\mathrm{NH}_{3}$. Several crossensitivities were demonstrated:

Fig. 14 - with increasing $\mathrm{NO}_{2}$ the CPK-sensor shows lower NOx-concentrations, than CLD.

Fig. 15 - with higher $\mathrm{NH}_{3}$ content the $\mathrm{CPK}$-sensor shows higher NOx-concentrations, than CLD.

Another finding was, that with increasing content of $\mathrm{NH}_{3}, \mathrm{CLD}$ shows slightly higher NOx readings, than FTIR.

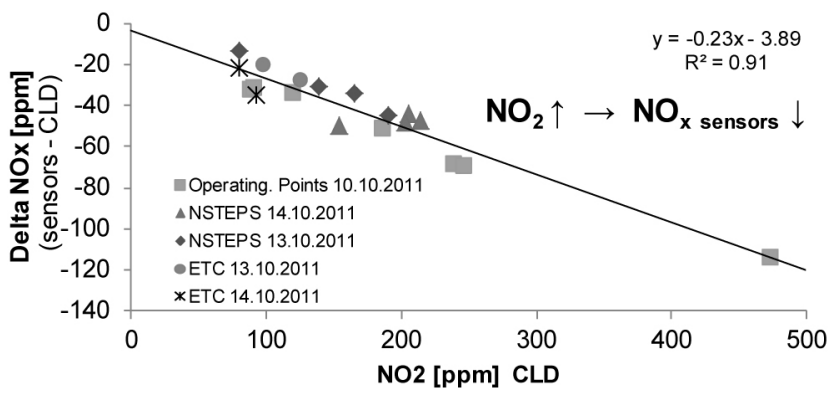

Figure 14. Cross-sensitivity of the NOx-sensor to $\mathrm{NO}_{2}$; Iveco $\mathrm{F} 1 \mathrm{C}$ Euro (4); ULSD

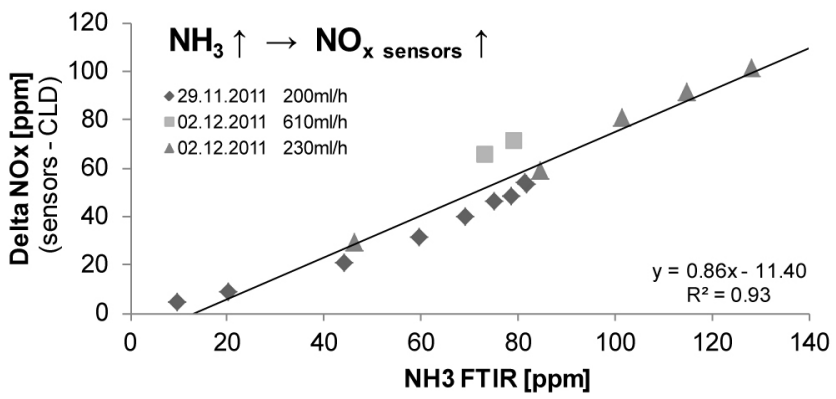

Figure 15. Cross-sensitivity of the $\mathrm{NOx}$-sensor to $\mathrm{NH}_{3}$; Iveco $\mathrm{F} 1 \mathrm{C}$ Euro (4); ULSD

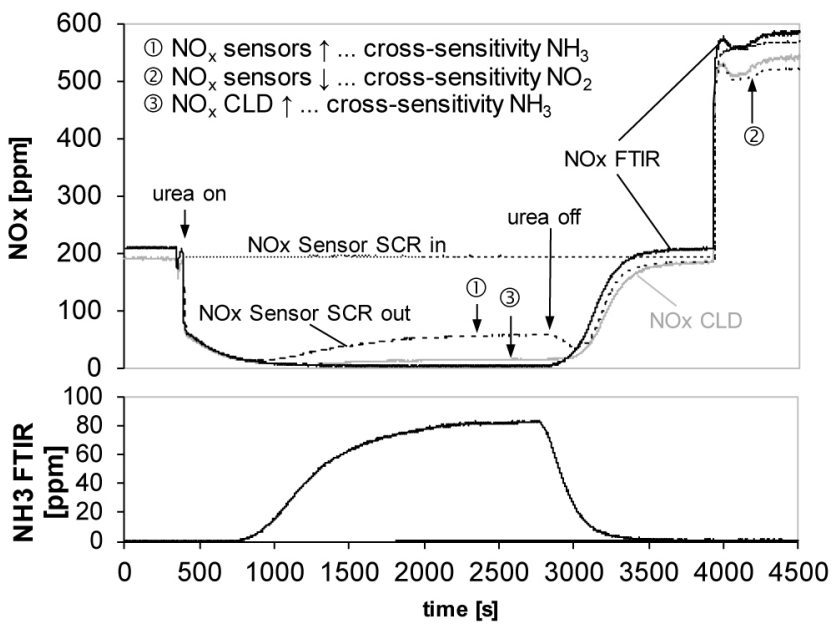

Figure 16. Example of Cross-Sensitivity during $\mathrm{NH}_{3}$ Storage at OP1 Iveco F1C Euro (4); ULSD

Fig. 16 shows an example of crossensitivities at SW on \& off in the test, which is described in Fig. 12 - RAI at low-load OP1, SW off, stabilization at OP1, load jump to the high-load OP2 (without RAI). The deviations of signals caused by the crossensitivites are visible:

1. CPK - sensor indicates higher NOx-values due to crossinfluence of $\mathrm{NH}_{3}$,

2. CPK - sensor indicates lower NOx-values due to crossinfluence of $\mathrm{NO}_{2}$ (there are no RAI and no $\mathrm{NH}_{3}$ at OP2),

3. due to the presence of $\mathrm{NH}_{3}$ CLD shows slightly higher NOxvalues than FTIR. 


\section{Cleaning of the System}

Dependent on temperature different solid residues can be created from the injected urea. According to [17] these are:

- $130-230^{\circ} \mathrm{C}$ crystals of Urea \& Biuret

- 200-350 ${ }^{\circ} \mathrm{C}$ Cyanuric Acid

- $200-450^{\circ} \mathrm{C}$ Ammelid, Ammelin, Melanin

Urea crystallization typically takes place at low temperatures. If there is insufficient mixture preparation and wall wetting, than it is very likely that crystallization happens. The activation of RAI at $200^{\circ} \mathrm{C}$ is first of all to prevent the crystallization at lower temperature.

At higher temperatures other residues can be created. Some of them can be melted and evaporated and take part on the chemical reactions. Some others are difficult to remove even at high temperatures.

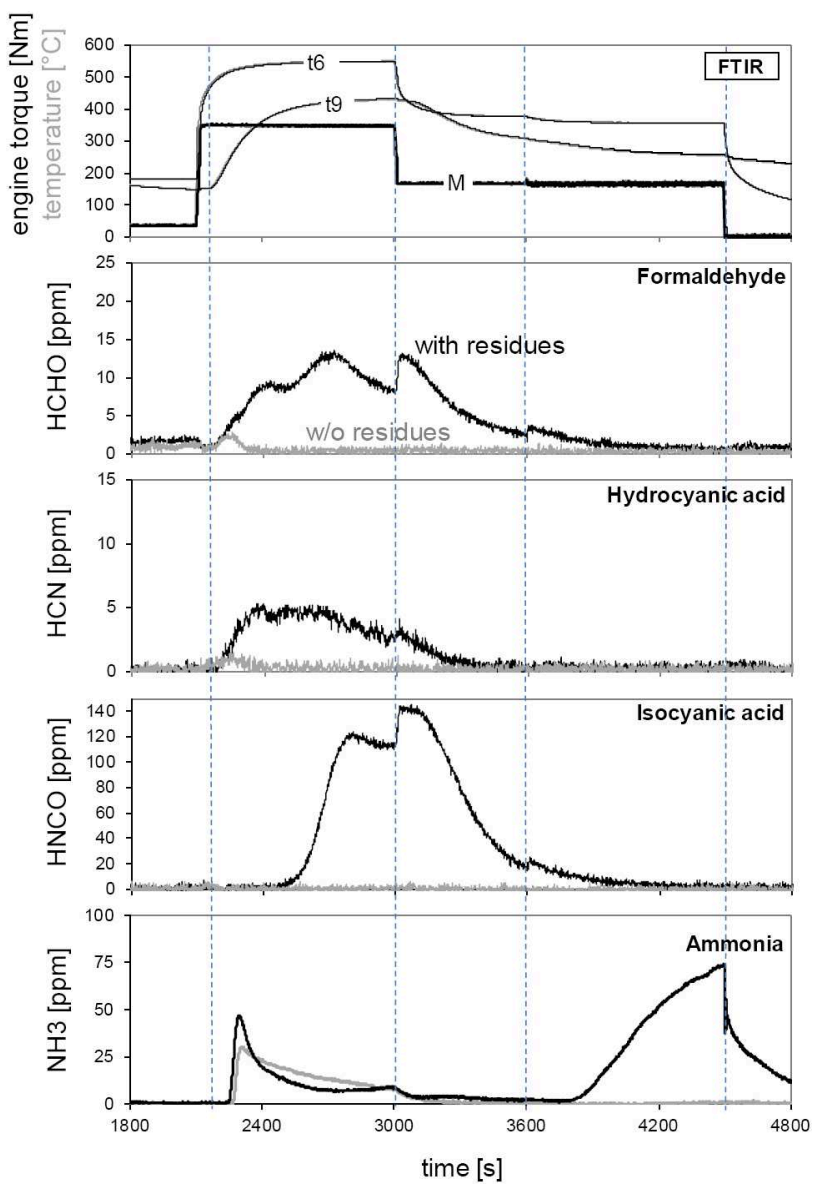

Figure 17. Comparison of Unregulated Emissions in 4 Pts-TEST with \& without residues, SCR with AdBlue Injection, Iveco F1C E(4); ULSD

In a research work on one of the investigated SCR-systems different dosings (and also overdosings) of AdBlue happened. In the following 4-pts test exceptionally high peak values of some unregulated emissions resulted (Formaldehyde, Hydrocyanic Acid and Isocyanic Acid).
After "cleaning" of the system - heating up at full load during 30 minutes, without urea dosing - the test was repeated.

Fig. 17 shows the results: after cleaning there are no significant emissions of the critical components.

The cleaning is recommended at the beginning of every basic test on the engine dynamometer.

\section{Results at Different Steptests}

The validation of $\mathrm{K}_{\mathrm{NOX}}$ in 4-pts or in 6-pts test is represented in Fig. 18. (4-pts. according to Fig. 2; 6-pts according to Fig.4). At low-load OP's with deactivated RAl the NOx reduction rate is near to zero. At higher OP's the full efficiency is attained.

Principally there is no difference for the validation to apply any of those steps tests. For reasons of comparability it is recommended to always use the same test schedule for the same tested system.

In this schedule the same duration of "cleaning" and the same sequence and duration of the load steps should be applied.
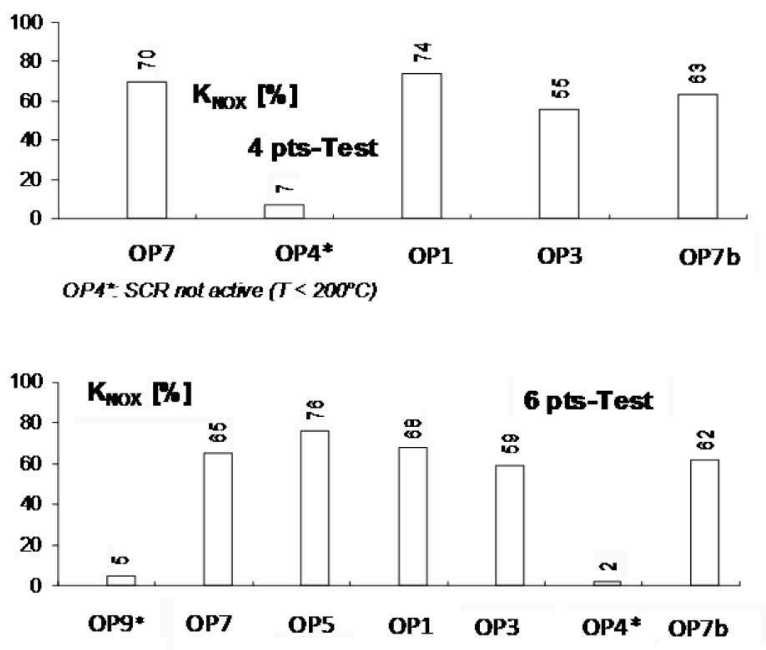

OPG: OPA: SCR not active $\left(T<200^{\circ} \mathrm{C}\right)$

Figure 18. Validation of the NOx-reduction rate in 4-points- and in 6-points test

\section{Secondary Emissions with Cu- \& Fe-zeolites}

Secondary emissions and traces (in ppb range) are investigated as a part of VERT / LRV quality verification procedure for DPF- and SCR-systems. The sampling and analytics are performed by a specialized team of EMPA Analytical Laboratory for Organic Chemistry. There are 3 groups of secondary emissions, which are known as very carcinogen and toxic:

- Polycyclic Aromatic Hydrocarbons PAH, 12 substances *), [ $\mu \mathrm{g} / \mathrm{L}]$,

- Nitro-PAH, 22 substances $[\mu \mathrm{g} / \mathrm{L}]$,

- Polychlorinated Dibenzodioxins PCDD and Polychlorinated Dibenzofurans PCDF, 33 substances ${ }^{*}$, [pg/L]. 
VERT Secondary Emissions Tests were performed with urea based SCR systems (without DPF).

One of the systems used a Cu-zeolite and the other one a Fe-zeolite as SCR-catalyst.

Samples were taken continuously proportional to the actual gas flow (aliquot) from the undiluted hot exhaust gas. A volume of typically 5-8 $\mathrm{Nm}^{3}$ was collected through a validated sampling arrangement over 200 minutes driving cycle time (2 full ISO 8178/4 C1-cycles).

The sampling device consists of a sampling tube, cooler, condensate separator, filter stage and two-stage adsorber unit (XAD-2). The sampling apparatus, made from glass is extensively cleaned and heated to high temperatures prior to each sampling (heating in steps up to $450^{\circ} \mathrm{C}$ ). Using marked PCDD-standards in this investigation the recovery was found to be $65+10 \%$.

The same sample was used to determine the PCDD/F as well as the $\mathrm{PAH}$.

PCDD/F-analysis was performed by separating the toxicologically relevant $\mathrm{PCDD} / \mathrm{F}$ isomers using gas chromatography followed by high resolution mass spectrometry.

After chromatographic work-up quantitative analysis of the $\mathrm{PAH}$ and Nitro-PAH were also performed using capillary gas chromatography high resolution mass spectrometry.

\section{PCDD/F-Analysis}

The following graph, Figure 19, shows the overall results.

\section{2,3,7,8-PCDD/Fs (TEQ-Sum)}

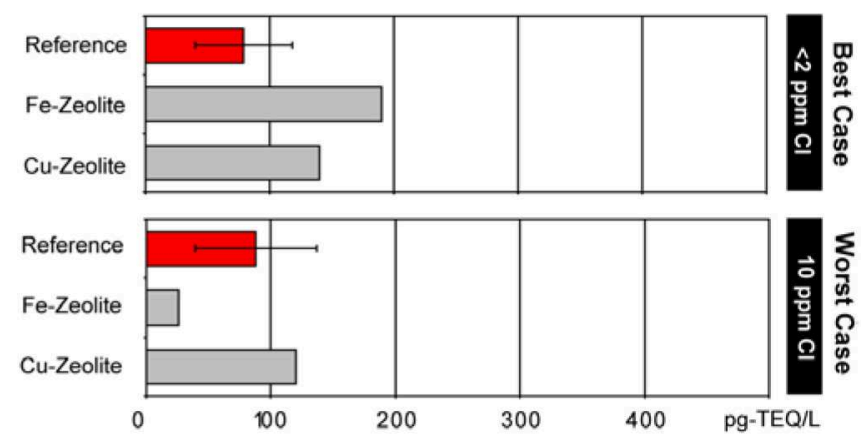

Figure 19. Emission factors for the weighted sum of 2,3,7,8-substituted $\mathrm{PCDD} / \mathrm{Fs}$ (TEQ sum) in pg/L. Emissions of iron- and copper-zeolites are compared with engine-out emissions (reference) for fuels with chlorine levels of $<2$ and $10 \mu \mathrm{g} / \mathrm{g}$.

PCDD/F emissions (TEQ sum) of the engine accounted for $80 \pm 40 \mathrm{pg}-\mathrm{TEQ} / \mathrm{L}$ with reference fuel (best case) and $90 \pm 50$ pg-TEQ/L with chlorine-doped fuel (worst case). As shown in Fig. 19, PCDD/F emissions of configurations with iron- and copper-zeolites are at or below respective engine-out emissions. Even under worst case conditions, when using chlorine-doped fuels, no substantial increase of the PCDD/F emissions was noticed.

\section{PAH-Analysis}

$\mathrm{PAH}$ were analysed from the same sample as the PCDD/F. The following graph, Fig. 20, summarizing the data for the carcinogenic PAH according to the IARC-definition shows the overall results.

The analysis of the broad class of polycyclic aromatic hydrocarbons (PAHs) was limited to those 4- to 7-ring PAHs, which are rated to be carcinogenic to humans by the US EPA. Among these compounds, we quantified emissions of benzo(a) anthracene, benzo(b)fluoranthene, benzo(k)fluoranthene, benzo(a)pyrene, di-benzo(a,h)anthracene, indeno(1,2,3-c,d) pyrene, and chrysene.

\section{Genotoxic PAHs (Sum according to EPA)}

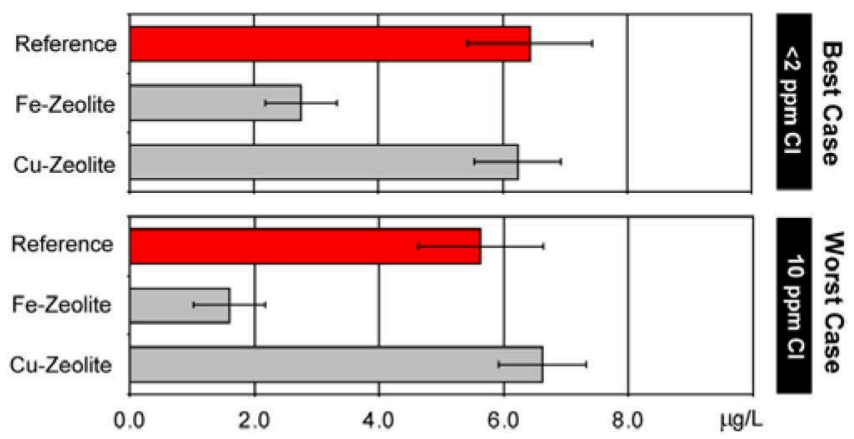

Figure 20. Emission factors for the sum of carcinogenic PAHs (EPA) in $\mu \mathrm{g} / \mathrm{L}$. Emissions of iron- and copper-exchanged zeolites are compared with engine-out emissions (reference) for fuels with chlorine levels of $<2$ and $10 \mu \mathrm{g} / \mathrm{g}$.

Fig. 20 illustrates the effects on genotoxic PAH emissions when applying both deNOx systems. Compared to the reference configurations, the iron-zeolite reduced the emissions of carcinogenic PAHs by about $70 \%$, whereas the copper-zeolite did not convert these PAHs. The chlorine-doped fuel had no substantial effects on emissions of these PAHs.

\section{Quality of a Retrofit System After 1000h}

(DPF+SCR) system retrofitted on bus was measured on a HD chassis dynamometer before and after the durability test of $1000 \mathrm{~h}$ road application. Table 4 summarizes the most important results: there is a negligible reduction of the deNOxefficiency and there are no significant secondary emissions of $\mathrm{NH}_{3} \& \mathrm{~N}_{2} \mathrm{O}$. It can be stated, that there is no deterioration of the SCR-system after 1000h. The used DPF was VERT/OAPC approved and always had the excellent particle counts filtration efficiency of $99.6 \%$. 
Table 4. Efficiency and non-regulated emissions of a retrofit VSCR system before and after $1000 \mathrm{~h}$ field test; overall average PCFE = $99.6 \%$

\begin{tabular}{|c|c|c|c|c|c|c|}
\hline $\begin{array}{l}\text { VERT } \\
\text { dePN }\end{array}$ & $\alpha$ & \multicolumn{2}{|l|}{ TEST } & $\begin{array}{l}\text { SCR } \\
K_{\text {NOx }} \\
{[\%]}\end{array}$ & $\begin{array}{l}\mathrm{NH}_{3} \\
\max \\
{[\mathrm{ppm}]}\end{array}$ & $\begin{array}{l}\mathrm{N}_{2} \mathrm{O} \\
\max \\
{[\mathrm{ppm}]}\end{array}$ \\
\hline \multirow{5}{*}{$\begin{array}{l}\text { VPNT2 } \\
\text { Vehicle } \\
\text { chassis- } \\
\text { dynamo } \\
\text { meter. }\end{array}$} & 0.75 & $44 \mathrm{~km} / \mathrm{h}$ & stat. & 82 & 0 & 2 \\
\hline & 0.75 & $78 \mathrm{~km} / \mathrm{h}$ & stat. & 92 & $\begin{array}{c}8-26 \\
\text { (deposits) }\end{array}$ & 2 \\
\hline & 0.75 & SWON & stat. & 79 & - & - \\
\hline & 0.85 & SWON & stat. & 97 & - & - \\
\hline & 0.75 & FIGE & dyn. & - & 5 & 2 \\
\hline \multicolumn{4}{|c|}{ Averages } & 87.50 & 11.00 & 2.00 \\
\hline \multirow{5}{*}{$\begin{array}{l}\text { VPNT3 } \\
1000 \mathrm{~h} \\
\text { Vehicle } \\
\text { chassis- } \\
\text { dynamo } \\
\text { meter. }\end{array}$} & 0.75 & $44 \mathrm{~km} / \mathrm{h}$ & stat. & 81 & 0 & 2 \\
\hline & 0.75 & $78 \mathrm{~km} / \mathrm{h}$ & stat. & 90 & $\begin{array}{c}5-21 \\
(\text { deposits) }\end{array}$ & 2 \\
\hline & 0.75 & SWON & stat. & 76 & - & - \\
\hline & 0.85 & SWON & stat. & 85 & - & - \\
\hline & 0.75 & FIGE & dyn. & $63-92$ & 5.2 & 1.7 \\
\hline \multicolumn{4}{|c|}{ Averages } & 81.9 & 9.10 & 1.90 \\
\hline
\end{tabular}

\section{Conclusions}

Following conclusions can be pointed out:

\section{VERTdePN}

The most important statements are:

- the procedures for the quality verification of SCR-, or (DPF+SCR) - systems are developed and confirmed,

- these test procedures on HD-chassis dynamometer and onroad are useful for OEM- and for retrofit systems,

- engine dynamometer testing enables the deepest insight in the investigated system concerning: secondary- and nonlegislated emissions, variations of feed factor, analysis on different sampling positions and at specific engine operating conditions (like legal test procedures),

- testing on HD-chassis dynamometer can partially replace the engine dynamometer depending on the possibilities of the installation,

- testing of SCR-systems on vehicle is important, because of urea dosing, urea mixing and electronic control,

- the filtration efficiency of a DPF is independent of the operating condition (except of regeneration period, or passing over the maximum space velocity),

- the NOx reduction efficiency of SCR-systems is dependent on the operating conditions, because of the optimal temperature window of the SCR-catalysis; at the conditions with exhaust temperature below $200^{\circ} \mathrm{C}$ the urea dosing is stopped.

\section{Different Research Subjects}

\section{EGR}

- EGR reduces NOx and increases the particle engine-out emissions,

- EGR is most advantageous at low load, when SCR is not active.

\section{Ammonium Hydroxide}

- in order to obtain a stoichiometric feed factor with $10 \%$ solution Ammonium Hydroxide $\left(10 \% \mathrm{NH}_{3}\right)$ it is necessary to increase the injected volumetric flow, comparing to AdBlue, by approx. factor 4 ,

- in the useful range of the feed factor $\alpha$ around 0.8 there is a slightly lower $\mathrm{K}_{\mathrm{NOx}}$ with $\left(10 \% \mathrm{NH}_{3}\right) ; \Delta \mathrm{K}_{\mathrm{NOx}} \approx 1-3 \%$,

- with $\left(10 \% \mathrm{NH}_{3}\right)$ there are also slightly higher values of $\mathrm{NOx}$ \& $\mathrm{NO}_{2}$, but there is almost no NH3-slip approaching the stoichiometric feed factor $\alpha=1$,

- there are: the higher readings of $\mathrm{NOx} \& \mathrm{NO}_{2}$ with FTIR and the equal estimate of $\mathrm{K}_{\mathrm{NOX}}$ with CLD and with FTIR.

\section{$\mathrm{NH}_{3}$-Storage}

- at low-load OP1 with RAI there is a storage of $\mathrm{NH}_{3}$ in the SCR catalyst,

- after load increase to OP2 there is $\mathrm{NH}_{3}$ release due to the increasing exhaust temperature; this release is indicated by transitory NOx-reduction effect without RAI.

\section{Crossensitivities}

- CPK-sensor indicates lower NOx-concentrations under influence of $\mathrm{NO}_{2}$ and higher $\mathrm{NOx}$-concentrations under influence of $\mathrm{NH}_{3}$,

- CLD indicates slightly increased NOx-readings under influence of $\mathrm{NH}_{3}$.

\section{Testing}

- cleaning of the SCR-system from the possible residues (FL w/o RAI) is recommended at the beginning of test on the engine dynamometer,

- it is possible to use different stationary steps tests - for reasons of comparability it is recommended to always use the same test schedule for the same tested system,

- there were no significant secondary emissions of traces (PCDD/F), or genotoxic PAHs with all investigated SCRcatalysts (V, Cu \& Fe),

- an excellent quality of a retrofitted VSCR-system after 1000h durability test was confirmed.

\section{Acknowledgement}

The authors want to express their gratitude for the financial support and realisation of the project to the:

- Swiss Federal Office of Environment BAFU, Mr. D. Zürcher

- Swiss Federal Office for Roads ASTRA, Mr. Th. Gasser

- Swiss Occupational Insurance SUVA, Mrs. I. Schärli 
Further thanks are expressed to:

- IVECO Switzerland for the research engine and help with engine setting

Mr. M. Signer, Mr. E. Mathis, Mr. R. Zellweger

\section{References}

1. www.lowemissionzones.eu

2. Jacob, E.; Müller, R.; Scheeder, A.; Cartus, T.; Dreisbach, R.; Mai, H.-P.; Paulus, M.; Spengler, J.: High Performance SCR Catalyst System: Elements to Guarantee the Lowest Emissions of NOx. 27. Internationales Wiener Motorensymposium 2006. Bd.2.

3. Cartus, T.; Schüssler, M.; Herrmuth, H.; Giovanella, M.: SCR and DPF - From Concept to Production. Mastering Complex, Mutli-Dimensional Challenges. 28. Intern. Wiener Motorensymposium 2007. Bd.1.

4. Pischinger, S., Körfer, T., Wiartalla, A., Schnitzler, J. et al., "Combined Particulate Matter and NOx Aftertreatment Systems for Stringent Emission Standards," SAE Technical Paper 2007-01-1128, 2007, doi:10.4271/2007- 01-1128.

5. Hosoya, M., Kawada, Y., Sato, S., and Shimoda, M., "The Study of NOx and PM Reduction Using Urea Selective Catalytic Reduction System for Heavy Duty Diesel Engine," SAE Technical Paper 2007-01-1576, 2007, doi:10.4271/2007-01-1576.

6. Lopez, M.: HDD On- \& Off-Road SCR Systems - Euro 6/ Stage IV and Beyond. International CTI Conference "SCR Systems", Munich, D, July 2012.

7. Folic, M.: Combined Systems Relying on SCR for Efficient DeNOx : Results and Prospects. International CTI Conference "SCR Systems", Munich, D, July '2012.

8. Robb, L.; Görsmann, C.: Retrofit SCRT System with Optimised Secondary Emissions. International CTI Conference "SCR Systems", Munich, D, July 2012.

9. Müller-Hass, K.; Holz, O.: High-Performance SCR Technology with Ultra-Low NOx Emissions for Future Regulations. International CTI Conference "Emission Reduction for Off-Highway Applications”, Lindau, D, Sept. 2012

10. Larsen, L. Ch.: Development of a Future Complete Exhaust System Solution including a SCR-F based on High Porous Silicon Carbide Filter Substrates. International CTI Conference "Emission Reduction for Off-Highway Applications”, Lindau, D, Sept. 2012.

11. Zimmermann, F. P.: SCR Technologies in Comparison: A detailed Investigation of the Influence of Feed Gas Composition on NOx Conversion Comparing Three Series SCR Technologies. 3. VDI-Fachkonferenz "Abgasnachbehandlungssysteme 2012" Stuttgart, D, Dec. 2012.

12. Balenovic, M.: Stretching the Challenge for SCR Based Aftertreatment Systems. 3. VDI-Fachkonferenz "Abgasnachbehandlungssysteme 2012" Stuttgart, D, Dec. 2012.
13. Görsmann, C.; Rawson, S; Robb, L.; Taylor, M.: RetrofitSCRT ${ }^{\circledR}$-System with Minimised Sekondary Emissions $\left(\mathrm{NH}_{3}\right.$, $\mathrm{NO}_{2}, \mathrm{~N}_{2} \mathrm{O}$ ). $10^{\text {th }}$ FAD Conference, Dresden, Nov. 2012

14. Testing particle filter systems for internal combustion engines. Swiss Norm SNR 277 205, Sept. 2007, final version $\mathrm{SN}_{2}$ 77206, Feb. 2011

15. Czerwinski, J.; Zimmerli, Y.; Mayer, A.; Heeb, N.; Lemaire, J.; D'Urbano, G.; Bunge, R.: Testing of Combined DPF+SCR Systems for HD-retrofitting - VERTdePN. SAE technical Paper 2009-01-0284, Detroit April 2009.

16. Czerwinski, J., Zimmerli, Y., Mayer, A., Heeb, N. et al., "Diesel Emission with DPF+SCR in VERTdePN - Testing \& Potentials," SAE Technical Paper 2011-01-1139, 2011, doi:10.4271/2011-01-1139.

17. Dorenkamp, R.; Hadler, J.; Rudolph, F.; Bühren, F.; Düsterdiek, Th.; Gehrke, V.; Kösters, M.; Kuiken, S. R.; Schütte, Th.: The New 2,0I TDI-Engine from Volkswagen to master Lowest Emissionsstandards in Europe. 17. Aachener Kolloquium Fahrzeug- und Motorentechnik 2008, p.1197.

\section{Abbreviations}

adBlue $\AA$ - urea water solution $32.5 \%$

AEEDA - Association Européenne d'Experts en Dépollution des Automobiles, Belgium

AFHB - Abgasprüfstelle FH Biel, $\mathrm{CH}$

Air min - stoichiometric air requirement

ASTRA - Amt für Strassen, $\mathrm{CH}$, Swiss Road Authority

BAFU - Bundesamt für Umwelt, $\mathrm{CH}$ (FOEN)

BAT - best available technology

CFPP - cold filter plugging point

CLD - chemoluminescence detector

CPC - condensation particle counter

CPK - supplier of datalogging equipment

CR - common rail

DC - Diffusion Charging Sensor

dePN - de Particles + deNOx

DI - Direct Injection

DMA - differential mobility analyzer

DPF - Diesel Particle Filter

ECU - electronic control unit

EGR - exhaust gas recirculation

EMPA - Eidgenössische Material Prüf- und Forschungsanstalt (Federal Laboratories for Testing Materials)

EPA - Environmental Protection Agency

ETC - European Transient Cycle

FE - filtration efficiency

FID - flame ionization detector

FIGE - a non-standardized vehicle version of ETC, created by Forschungsinstitut für Geräusche und Erschütterungen

FL - full load

FOEN - Federal Office of Environment (BAFU) 
FTIR - Fourrier Transform Infrared Spectrometer

HD - heavy duty

HP - high pressure

IARC - International Association of Research on Cancer

$\mathrm{K}_{\text {Nox }}$ - NOx reduction rate $\left(\mathrm{NO}_{\text {Xin }}-\mathrm{NO}_{\text {Xout }}\right) / \mathrm{NO}_{\text {Xin }}$

$\mathbf{K}_{\mathrm{PC}}-\mathrm{PC}$ reduction rate $\left(\mathrm{PC}_{\text {in }}-\mathrm{PC}_{\text {out }}\right) / \mathrm{PC}_{\text {in }}$

LD - low duty

LDS - Laser Diode Spectrometer (for $\mathrm{NH}_{3}$ )

LEZ - low emission zones

LRV - Luftreinhalteverordnung (OAPC)

ME - Matter Engineering

MD19 - heated minidiluter

NanoMet - NanoMetnanoparticle summary surface analyser $(P A S+D C+M D 19) P A S+D C+$ sampling \& dilution unit

NP - nanoparticles < $999 \mathrm{~nm}$ (SMPS range)

OAPC - Swiss Ordinance on Air Pollution Control

OBD - on-board diagnostics

OEM - original equipment manufacturer

OP - operating point

PAH - polycylic aromatic hydrocarbons

PAS - Photoelectric Aerosol Sensor

PC - particle counts

PCDD/F - polychlorinated dibenzodioxines \& furanes

PCFE - particle counts filtration efficiency

PM - particulate matter, particle mass

PSD - particle size distribution

RAI - reduction agent injection

SCR - selective catalytic reduction

SMPS - Scanning Mobility Particle Sizer

SP - sampling position

SUVA - Schweiz. Unfallversicherungs-Anstalt (Swiss

Occupational Insurance)

SW - urea switch on/of

SWON - urea switch on

SWOFF - urea switch off

$\mathbf{t}_{\mathrm{amb}}$ - ambient temperature

TC - thermoconditioner.

TCI - turbocharging \& intercooling

$\mathbf{t}_{\text {exh }}$ - exhaust temperature

TeVeNOx - Testing of Vehicles with NOx reduction systems
TEQ - toxicity equivalence

TTM - Technik Thermische Maschinen

ULSD - ultra low sulfur Diesel

VERT - Verification of Emission Reduction Technologies; $\underline{\text { www. }}$ vert-dpf.eu

VERTdePN - VERT DPF + VERT deNOx

VPNT1 - VERTdePN Test 1

VPNT2 - VERTdePN Test 2 - field durability 1000h

VPNT3 - VERTdePN Test 3 - check after field test chassis dynamometer

VPNSET - VERTdePN secondary emissions test - engine dynamometer

VSET - VERT Secondary Emissions Test

WHTC - worldwide HD transient cycle

$\alpha$ - feed factor of urea dosing; ratio: urea injected / urea stoichiometric; calculated by the ECU.

The Engineering Meetings Board has approved this paper for publication. It has successfully completed SAE's peer review process under the supervision of the session organizer. The process requires a minimum of three (3) reviews by industry experts.

All rights reserved. No part of this publication may be reproduced, stored in a retrieval system, or transmitted, in any form or by any means, electronic, mechanical, photocopying, recording, or otherwise, without the prior written permission of SAE International.

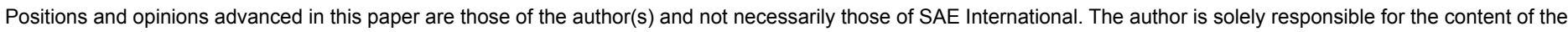
paper.

ISSN 0148-7191

http://papers.sae.org/2014-01-1579 